\title{
Computed Tomography Techniques Help Understand Wear Patterns in Retrieved Total
}

Knee Replacement

\section{Arianna Cerquiglini $^{1 *}$, Johann Henckel ${ }^{1}$, Harry Hothi ${ }^{1}$, Lorenzo Dall'Ava ${ }^{1}$, Paul Shearing ${ }^{2}$, Michael T.} Hirschmann ${ }^{3}$, Alister J. Hart ${ }^{1}$

${ }^{1}$ Institute of Orthopaedics and Musculoskeletal Science, University College London and the Royal National Orthopaedic Hospital, Stanmore, UK

${ }^{2}$ Electrochemical Innovation Lab, Department of Chemical Engineering, University College London, London UK

${ }^{3}$ Department of Orthopaedic Surgery and Traumatology, Kantonsspital Baselland (Bruderholz, Liestal, Laufen), Switzerland

*Corresponding Author:

Arianna Cerquiglini

Royal National Orthopaedic Hospital

Brockley Hill,

Stanmore, London,

HA7 4LP, United Kingdom

Phone: +44 (0) 2089095825 ,

Fax: +44 (0) 2089548560

Email: arianna.cerquiglini.15@ucl.ac.uk

Author Contributions:

All authors have read and approved the final manuscript. 


\section{Abstract}

\section{Introduction}

Suboptimal total knee arthroplasty (TKA) position of both femoral and tibial components is thought to be linked with poor clinical outcomes, polyethylene wear and the "unexplained" painful knee replacement. The aim of this study was to better understand the effect of implant orientation on knee implant performance.

\section{Materials and Methods}

We analysed 30 retrieved contemporary TKA implants. Implant positioning measurements in the coronal plane were made prior to revision using a diagnostic algorithm, based on 3D computed tomography $(\mathrm{CT})$ images. Each retrieved polyethylene component was imaged using a micro-CT scanner and a high resolution computational 3D model of each component was digitally reconstructed. The difference in thickness between medial and lateral components was calculated. Statistical analysis was performed to investigate the association between component positioning and damage patterns.

\section{Results}

We found a significant correlation between both the tibiofemoral and femoral angles and difference in thickness between polyethylene compartments: varus angulations were strongly associated with thinner medial compartments, whilst valgus angulations were associated with thinner lateral compartments. Moreover, suboptimal orientation tibiofemoral and tibial component angulation were associated to greater differences in thickness between polyethylene compartments.

\section{Conclusion}

Our study is the first to compare accurate 3D CT measurements of pre-revision TKA positioning in the coronal plane with post-revision retrieval analysis from innovative, accurate and highly reliable micro-CT based method. Our results demonstrate the impact of component positioning on polyethylene damage and helps understanding of the in vivo performance of these implants. 


\section{Introduction}

Polyethylene (PE) wear in total knee arthroplasty (TKA) remains a crucial issue: aseptic loosening linked to periprosthetic osteolysis has been reported to be one of the main reasons for revision TKA [1-2]. Among the most common reasons for increased PE wear are malposition and malorientation. Suboptimal TKA position of the femoral and tibial components contributes to poor outcomes, premature polyethylene wear and persistent pain after TKA [3-6]. In particular, malposition in the coronal plane was considered to be related to early aseptic loosening, which was explained by increased PE wear due to abnormal force distributions [7, 8].

In clinical practice, position and orientation of TKA is generally assessed using plain radiographs [9]. Several retrieval studies have assessed TKA implant orientation only by radiographs [7, 10]. However, highly accurate measurements are strictly dependent on the patient's position during imaging, as this influences the resulting projection. In fact, well aligned and reproducible anteroposterior and sagittal radiographs are rarely achieved. Moreover, measurements in the axial plane are not possible $[11,12]$. Routine assessment of TKA component position might also be performed on transverse CT slices (2D-CT) $[6,13,14]$. However, the identification of anatomical landmarks on the same CT slice is dependent on the orientation of the patient's limbs, anatomical variability and CT slice width [15]. Hirschmann et al. [11] recently demonstrated that the use of a low-dose 3D reconstructed CT is able to overcome these limitations.

Several retrieval studies have previously demonstrated the importance of TKA position for wear, but the clinical relevance of this relationship for long term survivorship remains controversial [10]. This may be due to the method chosen to assess the PE wear pattern. Although previous papers [10, 16] have used visual inspection and demonstrated that it can give an acceptable estimation about the quality of the damage, it may not be accurate enough to quantify the amount of wear [17]. Recently, the utility of alternative techniques, such as micro-CT scanning has been demonstrated $[18,19]$. 
The aim of this study was to correlate highly accurate measurement of pre-revision TKA position on CT in the coronal plane, provided by an established 3D imaging technique [11], with retrieval findings post-revision, provided by a novel micro-CT based method, in order to better understand implant orientation effects on knee implant performance.

\section{Methods}

Level of Evidence III.

Figure 1 shows the study design.

\section{MATERIALS}

Our retrieval cohort consisted of 30 TKA with symmetrical polyethylene tibial inserts, 22 were cruciate retaining (CR) and 8 posterior stabilized (PS) designs. They were obtained from 21 female and 9 male patients, with a median (range) age of 62 (43-78) years and a median (range) time to revision of 22 (5-162) months. The reasons for revision were instability $(n=11)$, malposition $(n=9)$, pain $(n=3)$, aseptic loosening $(n=3)$, patella maltracking $(n=3)$ and stiffness $(n=1)$. Table 1 summarizes the TKA and patient demographics for each case.

\section{D COMPUTED TOMOGRAPHY (CT) FOR POSITION ASSESSMENT}

Pre-revision CT scans of the knee from each patient were taken using the Imperial CT protocol [20]. This protocol allows a reduced radiation exposure by limiting the scanning to the mandatory fields including three anatomic regions, femoral head, knee and ankle. This allows identification of the mechanical axes of both femur and tibia. Metal artefact reduction sequences were applied in order to accurately visualize TKA metal components and, consequently, measure implant orientations.

From the CT images, the mechanical axes of both femoral and tibial components were defined, the images orientated towards standardised frames of references and the following components' orientation measured [3]: (1) degree of varus/valgus of femoral component, measured as the angle 
between a line connecting the femoral component distal condyles and a line perpendicular to the mechanical axis of the femur, Figure 2A; (2) degree of varus/valgus of tibial component, assessed as the angle between a line connecting the horizontal face of the tibial component and a line perpendicular to the mechanical axis of the tibia, Figure $2 \mathrm{~B}$ and (3) the tibiofemoral angle, identified as the angle between the mechanical axis of the femur and the mechanical axis of the tibia, Figure 2C. The measured values were classified in agreement with surgical standard aims [21]: varus and valgus angles $>3^{\circ}$ were considered sub-optimal position.

This method proved to have a near perfect intra- and inter-observer variability (ICC 0.96 to 0.99 and 0.89 to 0.97 , respectively) [11]. This method is reproducible and more reliable than traditional methods, such as measurements on radiographs or 2D-CT [11].

\section{MICRO COMPUTED TOMOGRAPHY (MICRO-CT) FOR RETRIEVAL ANALYSIS}

The method consisted of three stages: (1) micro-CT scanning of our retrieved cohort and data reconstruction, (2) volumetric rendering from micro-CT data and (3) analysis of 3D rendering. Figure 3 shows a flowchart explaining all the 3 stages of this micro-CT based method.

\section{Micro-CT Scanning and Volume Reconstruction}

All PE inserts were scanned using a micro-CT scanner (XTH 225, Nikon Metrology NV), Figure 3B. Scans included 3176 views in $0.11^{\circ}$ of increment, with one frame per view and a frame exposure of $1000 \mathrm{~ms}$. The X-ray tube voltage was set to $80 \mathrm{kV}$, with a current of $300 \mu \mathrm{A}$. Scans were reconstructed at the full $45-\mu \mathrm{m}$ isotropic resolution.

\section{Volumetric Rendering}

The volumetric reconstructions of each PE insert were analysed with 3D micro-CT analysis software (Simpleware ScanIP, software version 7.0, Exeter, UK); isosurface rendering was performed and the resulted geometry was saved in stereolithography (STL) file format, Figure 3C. 


\section{Volume Rendering Analysis: Difference in thickness}

Geomagic Control X (Geomagic Inc, Morrisville, NC, USA) was used to further analyse all volume renderings. Each image of PE inserts was imported as measured data, and a plane was created and placed parallel and coincident to the backside surface to serve as reference data, Figure 3D.

A 3D comparison between the tibial articular surface and the reference plane was then performed and a colour map representing relative distances generated, Figure $3 \mathrm{E}$. The thinnest point in both the medial and lateral compartments was identified and the difference in thickness between them computed, in order to establish the most deformed compartment. This deformation was considered as a combination of wear and creep: no distinction was made in the present study. This approach has been already adopted in previous studies $[10,22]$ : compartment thickness was measured with callipers and considered a good estimator of the magnitude of wear. However, our method is based on micro-CT technology, which has been shown to be highly accurate [18-19]. Moreover, our method provided a high resolution $(45 \mu \mathrm{m})$.

In order to assess the intra-observer reliability (degree of agreement among different measurements from the same rater), the intra-class correlation coefficient (ICC) of three observations on 19 samples from the same rater was calculated. The inter-observer reliability (degree of agreement among the raters) was established by calculating the ICC of the mean of the observations from two different raters on 19 samples.

\section{STATISTICAL ANALYSIS}

Statistical analyses were performed using Prism 7 (GraphPad, USA).

Potential correlations between differences in thickness and varus/valgus orientations of the components were investigated using non-parametric Kruskal-Wallis tests.

Looking at suboptimal (outside $\pm 3^{\circ}$ ) and normal (within $\pm 3^{\circ}$ ) implant alignments, potential differences in the difference of thickness were evaluated using non-parametric Mann-Whitney test. 
The level of significance for all statistical analyses was $\mathrm{p}<0.05$.

\section{Results}

\section{D COMPUTED TOMOGRAPHY (CT) FOR POSITION ASSESSMENT}

Results from pre-revision 3D CT images revealed that 50\% $(n=15)$ of femoral TKA components showed varus orientations with a median (range) value of $3^{\circ}\left(1^{\circ}-4^{\circ}\right), 30 \%(n=9)$ revealed valgus orientations with a median (range) value of $2^{\circ}\left(1^{\circ}-3^{\circ}\right)$ while $20 \%(n=6)$ had a neutral angulation. Four cases showed sub-optimal varus orientation.

$60 \%(n=18)$ of tibial TKA components showed varus orientation with a median (range) value of $2^{\circ}$ $\left(1^{\circ}-5^{\circ}\right), 30 \%(n=9)$ revealed valgus orientation with a median (range) value of $2^{\circ}\left(1^{\circ}-5^{\circ}\right)$ and only $10 \%(n=3)$ presented a neutral angulation. Sub-optimal varus and valgus orientations were reported in four and one cases, respectively.

Regarding the tibiofemoral angle, 66\% $(n=20)$ of the implants showed a varus angulation with a median (range) value of $3^{\circ}\left(1^{\circ}-10^{\circ}\right)$, whilst $30 \%(n=9)$ revealed valgus angulation with a median (range) value of $1^{\circ}\left(1^{\circ}-6^{\circ}\right)$. Only one case showed a neutral angulation. Sub-optimal varus and valgus angulation were reported in six and one cases, respectively.

Table 2 summarizes results from 3D-CT analysis.

\section{MICRO COMPUTED TOMOGRAPHY (MICRO-CT) FOR RETRIEVAL ANALYSIS}

\section{Volume Rendering Analysis: Difference in thickness}

Micro-CT data analysis revealed that $63 \%(n=19)$ of tibial inserts showed thinner medial compartments compared to the lateral sides, with a median value (range) of difference in thickness of $0.045 \mathrm{~mm}(0.0047 \mathrm{~mm}-3.75 \mathrm{~mm})$; whilst $37 \%(\mathrm{n}=11)$ of tibial inserts showed thinner lateral compartments compared to the medial ones, with a median value (range) of difference in thickness of $0.060 \mathrm{~mm}(0.0001 \mathrm{~mm}-0.139 \mathrm{~mm})$.

Table 3 summarizes results from micro-CT images. 
The method here presented proved to have a near perfect intra- and inter-observer variability $(\mathrm{ICC}=$ 0.98 to 0.99 , in both the cases).

We found a significant correlation between time to revision and difference in thickness $(\mathrm{p}=0.0017$, $\mathrm{r}=0.5474)$, Figure 4.

\section{STATISTICAL ANALYSIS}

\section{Correlations with Femoral TKA Orientation}

A significant correlation was found between orientation of femoral TKA components and difference in thickness between PE tibial compartments $(\mathrm{p}=0.0336, \mathrm{r}=0.3890)$ : a progression in the varus angulation was associated with a progressively thinner medial compartment, while a progression in the valgus angulation was associated with a progressively thinner lateral compartment, Figure 5.

Looking at suboptimal (outside $\pm 3^{\circ}$ ) and normal (within $\pm 3^{\circ}$ ) aligned femoral angles, no significant difference was found in the difference in thickness between medial and lateral compartments $(\mathrm{p}>0.9999)$.

\section{Correlations with Tibial TKA Orientation}

No significant correlation was found between orientation of tibial TKA components and difference in thickness between PE tibial compartments ( $\mathrm{p}=0.4436, \mathrm{r}=0.1453)$.

A significant difference was found between suboptimal (outside $\pm 3^{\circ}$ ) and normal (within $\pm 3^{\circ}$ ) tibial angles $(\mathrm{p}=0.0185)$ : the median value of the depth difference for cases of suboptimal orientation was higher than the median value related to normal orientation $(0.1140 \mathrm{~mm}$ and $0.0382 \mathrm{~mm}$ respectively), Figure 6.

\section{Correlations with Tibiofemoral Angle}

A significant correlation was found between the tibiofemoral angle and depth difference between medial and lateral PE compartments $(\mathrm{p}=0.0329, \mathrm{r}=0.3905)$ : greater varus angulations were 
significantly correlated with thinner medial PE compartments, while greater valgus angulations were significantly correlated with thinner lateral PE compartments (Figure 7). Figure 8 shows two examples of these correlations.

Suboptimal tibiofemoral angulation (outside $\pm 3^{\circ}$ ) showed a higher depth difference median value $(0.0382 \mathrm{~mm}$ vs $0.1140 \mathrm{~mm})$ when compared to normal tibiofemoral angulation (within $\left.\pm 3^{\circ}\right)$ : this difference was significant ( $\mathrm{p}=0.0472)$, Figure 9.

\section{Discussion}

This is the first study to correlate findings from two different CT modalities: we used medical 3DCT imaging to measure precisely implant orientation and an innovative, accurate and reliable micro-CT based method to analyse retrieved TKAs. We found significant correlations between the difference in polyethylene compartment thickness and tibiofemoral angle, as well as femoral angulation; the orientation of the single tibial component seemed to have minor effects on polyethylene deformation. Suboptimal tibial and tibiofemoral angulations were associated to greater differences in thickness.

Our results are in agreement with previous studies. Vandekerckhove et al. [10] found that their retrieved cohort showed an increased medial wear with greater varus alignment of the tibial component. D'Lima et al. simulated variations in knee kinematics due to malorientation in the coronal plane and found that the PE inserts in the malaligned groups had the highest wear rates [23]. Collier et al. demonstrated that the mean loss of polyethylene thickness in the retrieved medial compartment of both TKA and unicompartmental knee replacements was associated with postoperative angulation of the knee in the coronal plane [24].

Our results showed a significant correlation between the time to revision and difference in thickness. This demonstrated that deformation of tibial inserts under malorientation conditions could be exacerbated with time. A clear example of this in our cohort, had a difference in thickness of 3.495 
$\mathrm{mm}$ and the TKA had been implanted for more than 13 years. These conditions were linked to the worst case of varus tibiofemoral angulation $\left(10^{\circ}\right)$; surprisingly, both femoral and tibial components showed varus angulation $<3^{\circ}$ : it can be expected that this discrepancy between single and overall orientation could be exacerbated by the asymmetry in the polyethylene deformation through the time.

A strength of this study is that is the first paper using three dimensional computed tomography to assess implant orientation and position for correlation with retrieval findings. Other research groups have identified TKA position using more traditional techniques, such as x-ray [7, 8, 16, 26-29]. Imaging techniques based on three dimensional computed tomography (3DCT) have been recognised as the investigation of choice for assessing implant positioning in TKA: in fact, the method used in this study, due to its three-dimensional nature, allowed post-imaging reconstruction in all planes and therefore was less affected by positioning errors [3]. Moreover, the metal artefacts reduction applied allowed to easily identify metal components' geometry, as well as anatomical landmarks. In a comparison study between radiographs, 2D-CT and 3D-CT, Hirschmann et al. demonstrated that 3DCT was highly reliable, even in measuring components' axial rotations, and significantly better than 2D-CT; moreover, intra- and inter-observer variabilities were near to perfection [11].

The retrieval analysis method was based on micro computed tomography technology (micro-CT), which has been previously introduced as accurate and reliable technique for analysis of retrieved PE inserts. Engh et al. [19] demonstrated that micro-CT scans of retrieved TKA inserts and pristine inserts (used as a reference) can be used to determine volume and location of wear. However, they estimated the magnitude of manufacturer tolerances was approximately half the magnitude of the total wear on average. Teeter et al. [31] also demonstrated that, because of manufacturing variability, PE insert volumes could differ by $2 \%$ in the worst case and showed a maximum linear difference of $0.21 \mathrm{~mm}$. Greater variability was also identified when CAD models from manufactures were chosen as reference geometry [32]. The study by Teeter et al. developed a reverse-engineering technique to 
generate an average 3D tibial insert reference geometry obtained from unworn PE inserts. This solution minimised the variability to $8.3 \pm 12 \mu \mathrm{m}$ [33]. However, such a large availability of pristine samples is not given, especially in a retrieval study like the one presented here. Hence, manufacturing tolerances as well as the identification of the ideal reference geometry could remain an unsolved issue. It was aimed to identify the thinnest point of each compartment and compute the difference, using a plane as reference geometry, without need for a pristine sample or CAD model. Moreover, comparing two zones of the same insert, the effect of manufacturing tolerances could be considered limited. The method was based on the peer reviewed [10, 22, 34] concept that differences in thickness between medial and lateral compartments could be considered a good estimator of magnitude of polyethylene deformation. However, whilst in previous studies the thinnest points were identified by using a calliper, our micro-CT based method provided more accurate and precise measurement [1819], with high resolution $(45 \mu \mathrm{m})$. Additionally, it showed a near perfect intra- and inter-observer variability ( $\mathrm{ICC}=0.98$ to 0.99 , in both the cases).

This retrieval study has several limitations. Firstly, the absence of a strong correlation between the single tibial component orientation and difference in thickness between compartments may be due to the limited number of implants. This study does however provide useful information for future work, which should then involve larger retrieval numbers.

Secondly, our micro-CT method applies only to symmetrical polyethylene retrieval inserts. The method was based on the fact that symmetrical tibial inserts show no difference in thickness between medial and lateral compartment, an assumption which allowed us to attribute differences in thickness to difference in the amount of deformation (wear and/or creep). Future work is fundamental in order to develop a method in order to investigate also asymmetrical PE inserts and wear in its three dimensional nature.

Finally, 3DCT images were used to define implant orientation. Although it has been demonstrated to be more reliable and accurate than plain radiographs, it was not possible to obtain images of the leg 
in weight-bearing position. Gbejuade et al. demonstrated good agreement between weight-bearing lower limb full-length x-ray and CT scans, however in case of non weight-bearing malalignment may be underdetected, especially in cases of pronounced laxity and instability [35]. Recently, an innovative imaging technique, the $\operatorname{EOS}^{\circledR} 2 \mathrm{D} / 3 \mathrm{D}$ imaging system, was used in TKA for studying implant positioning and was validated for knee axis measurement after TKA [36-38]: it uses ultrasensitive multi-wire proportional chamber detector to detect X-rays, which allows to scan patients in standing position.

The clinical relevance and the effect on TKA performance of positioning of each individual component in six degrees of freedom is not clearly established. In particular, the effect of axial mismatch between femoral and tibial components is still poorly understood because measurement from traditional techniques are often inaccurate and the optimal rotational alignment target has not been defined. However, combining 3D-CT measurements of implant orientation with retrieval results from micro-CT might allow to better understand the direct effect of malrotation and malposition on the three-dimensional nature of wear pattern.

\section{Conclusion}

This study compared TKA implant position measured using an established 3D-CT technique with retrieval findings from an innovative micro-CT based method. We investigated whether there was a relationship between TKA position in the coronal plane and the relative compartmental change in shape (i.e. deformation) in symmetrical PE inserts. A significant correlation was found for varus/valgus position and PE deformation. These results indicate that TKA position and orientation directly affects PE damage patterns and, thus, its performance in vivo. 


\section{Acknowledgements}

The authors are grateful to Dr. Francesco Iacoviello and Dr. Xuekun Lu for their valuable help and support in micro-CT data collection during this study.

\begin{tabular}{|c|c|c|c|c|c|}
\hline$\underset{\#}{\text { Implant }}$ & Design & Gender & $\begin{array}{c}\text { Age } \\
\text { [years] }\end{array}$ & $\begin{array}{c}\text { Time of } \\
\text { implantation } \\
\text { [months }]\end{array}$ & Reason for revision \\
\hline 1 & $\begin{array}{c}\text { PFC Sigma, DePuy, } \\
\text { CR }\end{array}$ & $\mathrm{F}$ & 68 & 15 & Aseptic loosening \\
\hline 2 & $\begin{array}{c}\text { PFC Sigma, DePuy, } \\
\text { CR }\end{array}$ & M & 66 & 53 & Malposition \\
\hline 3 & $\begin{array}{c}\text { Triathlon, Stryker, } \\
\text { PS }\end{array}$ & $\mathrm{F}$ & 53 & 79 & Instability \\
\hline 4 & $\begin{array}{c}\text { Triathlon, Stryker, } \\
\text { PS }\end{array}$ & M & 75 & 99 & Aseptic loosening \\
\hline 5 & $\begin{array}{c}\text { BalanSys, Mathys, } \\
\text { CR }\end{array}$ & $\mathrm{F}$ & 61 & 40 & Patella maltracking \\
\hline 6 & $\begin{array}{c}\text { PFC Sigma, DePuy, } \\
\text { CR }\end{array}$ & $\mathrm{F}$ & 46 & 20 & Pain \\
\hline 7 & $\begin{array}{l}\text { TC PLUS, Smith \& } \\
\text { Nephew, CR }\end{array}$ & M & 62 & 10 & Instability \\
\hline 8 & $\begin{array}{c}\text { Signature, Biomet, } \\
\text { PS }\end{array}$ & M & 64 & 10 & Malposition \\
\hline 9 & $\begin{array}{c}\text { NexGen LPS FLEX, } \\
\text { Zimmer, PS }\end{array}$ & $\mathrm{F}$ & 51 & 6 & Pain \\
\hline 10 & $\begin{array}{l}\text { LCS Complete, } \\
\text { DePuy, CR }\end{array}$ & $\mathrm{F}$ & 71 & 24 & Patella maltracking \\
\hline 11 & $\begin{array}{l}\text { LCS Complete, } \\
\text { DePuy, CR }\end{array}$ & $\mathrm{F}$ & 63 & 162 & Varus Instability \\
\hline 12 & $\begin{array}{l}\text { LCS Complete, } \\
\text { DePuy, CR }\end{array}$ & $\mathrm{F}$ & 70 & 12 & Instability \\
\hline 13 & $\begin{array}{c}\text { PFC Sigma, DePuy, } \\
\text { PS }\end{array}$ & $\mathrm{F}$ & 53 & 45 & Malposition \\
\hline 14 & $\begin{array}{c}\text { PFC Sigma, DePuy, } \\
\text { CR }\end{array}$ & $\mathrm{F}$ & 62 & 60 & Instability \\
\hline 15 & $\begin{array}{c}\text { PFC Sigma, DePuy, } \\
\text { CR }\end{array}$ & $\mathrm{F}$ & 72 & 19 & Stiffness \\
\hline 16 & $\begin{array}{c}\text { PFC Sigma, DePuy, } \\
\text { PS }\end{array}$ & $\mathrm{F}$ & 63 & 61 & Aseptic loosening \\
\hline 17 & $\begin{array}{c}\text { PFC Sigma, DePuy, } \\
\text { PS }\end{array}$ & $\mathrm{F}$ & 49 & 17 & Instability \\
\hline 18 & $\begin{array}{c}\text { PFC Sigma, DePuy, } \\
\text { CR }\end{array}$ & $\mathrm{F}$ & 67 & 13 & Patella maltracking \\
\hline 19 & $\begin{array}{c}\text { PFC Sigma, DePuy, } \\
\text { CR }\end{array}$ & $\mathrm{F}$ & 61 & 10 & Instability \\
\hline 20 & $\begin{array}{c}\text { Attune, DePuy, } \\
\text { PS }\end{array}$ & $\mathrm{F}$ & 78 & 5 & Instability \\
\hline
\end{tabular}




\begin{tabular}{|c|c|c|c|c|c|}
\hline 21 & $\begin{array}{c}\text { BalanSys, Mathys, } \\
\text { CR }\end{array}$ & M & 74 & 38 & Malposition \\
\hline 22 & $\begin{array}{c}\text { PFC Sigma, DePuy, } \\
\text { CR }\end{array}$ & M & 43 & 22 & Malposition \\
\hline 23 & $\begin{array}{c}\text { Triathlon, Stryker, } \\
\text { CR }\end{array}$ & M & 66 & 78 & Malposition \\
\hline 24 & $\begin{array}{c}\text { Attune, DePuy, } \\
\text { CR }\end{array}$ & $\mathrm{F}$ & 64 & 22 & Instability \\
\hline 25 & $\begin{array}{c}\text { Triathlon, Stryker, } \\
\text { CR }\end{array}$ & $\mathrm{F}$ & 50 & 7 & Pain \\
\hline 26 & $\begin{array}{c}\text { Attune, DePuy, } \\
\text { CR }\end{array}$ & $\mathrm{F}$ & 62 & 24 & Instability \\
\hline 27 & $\begin{array}{c}\text { BalanSys, Mathys, } \\
\text { CR }\end{array}$ & M & 59 & 15 & Malposition \\
\hline 28 & $\begin{array}{c}\text { BalanSys, Mathys, } \\
\text { CR }\end{array}$ & $\mathrm{F}$ & 62 & 18 & Malposition \\
\hline 29 & $\begin{array}{c}\text { BalanSys, Mathys, } \\
\text { CR }\end{array}$ & M & 56 & 23 & Instability \\
\hline 30 & $\begin{array}{c}\text { BalanSys, Mathys, } \\
\text { CR }\end{array}$ & $\mathrm{F}$ & 53 & 22 & Instability \\
\hline
\end{tabular}

Table 1: Implant and patient demographics.

\begin{tabular}{c|ccc}
\multicolumn{5}{|c}{ Orientation $\left[^{\circ}\right.$ ] } \\
\hline Implant & Femoral & Tibial & Tibiofemoral \\
$\#$ & component & component & angle \\
1 & -1 & -3 & -2 \\
2 & -1 & -4 & -2 \\
3 & 0 & -5 & -4 \\
4 & -4 & -2 & -4 \\
5 & 2 & 5 & 1 \\
6 & -3 & -2 & -7 \\
7 & -3 & -1 & -3 \\
8 & 1 & -2 & -2 \\
9 & 3 & 2 & 6 \\
10 & -3 & -3 & -3 \\
11 & -3 & -1 & -10 \\
12 & -1 & 0 & 1 \\
13 & -4 & 0 & -3 \\
14 & 2 & -3 & -1 \\
15 & -4 & 2 & -2 \\
16 & 2 & 3 & -3 \\
17 & 1 & -1 & 1 \\
18 & 0 & 1 & 1 \\
19 & -2 & -4 & -4 \\
20 & 2 & -2 & 1 \\
21 & 2 & -1 & 0
\end{tabular}




\begin{tabular}{c|ccc}
22 & -4 & 1 & -1 \\
23 & -3 & -1 & -3 \\
24 & -1 & -5 & -6 \\
25 & -1 & 0 & -1 \\
26 & 0 & 1 & 2 \\
27 & 0 & -1 & -2 \\
28 & 0 & -3 & -3 \\
29 & 0 & 3 & 1 \\
30 & 1 & 3 & 1
\end{tabular}

Table 2: Results from 3DCT images in the coronal plane divided according to the angle considered: negative values mean varus angulation, whilst positive values means valgus angulation.

Micro-CT evaluation

\begin{tabular}{c|c} 
Implant \# & $\begin{array}{c}\text { Difference in thickness } \\
{[\mathrm{mm}]}\end{array}$ \\
1 & -0.0297 \\
2 & 0.0880 \\
3 & -0.0546 \\
4 & -0.6266 \\
5 & 0.1389 \\
6 & -0.0421 \\
7 & -0.0307 \\
8 & -0.1909 \\
9 & 0.0704 \\
10 & -0.0252 \\
11 & -3.495 \\
12 & 0.0084 \\
13 & 0.0155 \\
14 & 0.1041 \\
15 & -0.0177 \\
16 & -0.0068 \\
17 & -0.0152 \\
18 & 0.0073 \\
19 & 0.0529 \\
20 & $-0,0047$ \\
21 & -0.29 \\
22 & -0.0462 \\
23 & -0.15 \\
24 & 0.114 \\
25 & -0.042 \\
26 & -0.1 \\
27 & 0.06 \\
& \\
&
\end{tabular}




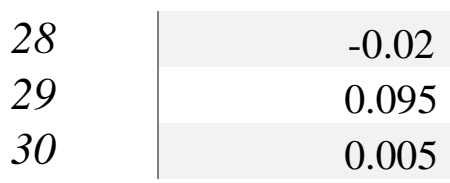

Table 3: Results from micro-CT data analysis showing for each case the difference in thickness between medial and lateral compartments $[\mathrm{mm}]$, calculate as thinnest point medial $_{-}$thinnest $_{\text {point }}$ lateral . Negative values mean that the medial compartment was thinner than the lateral one, whilst positive values mean that the lateral compartment was thinner than the medial one.

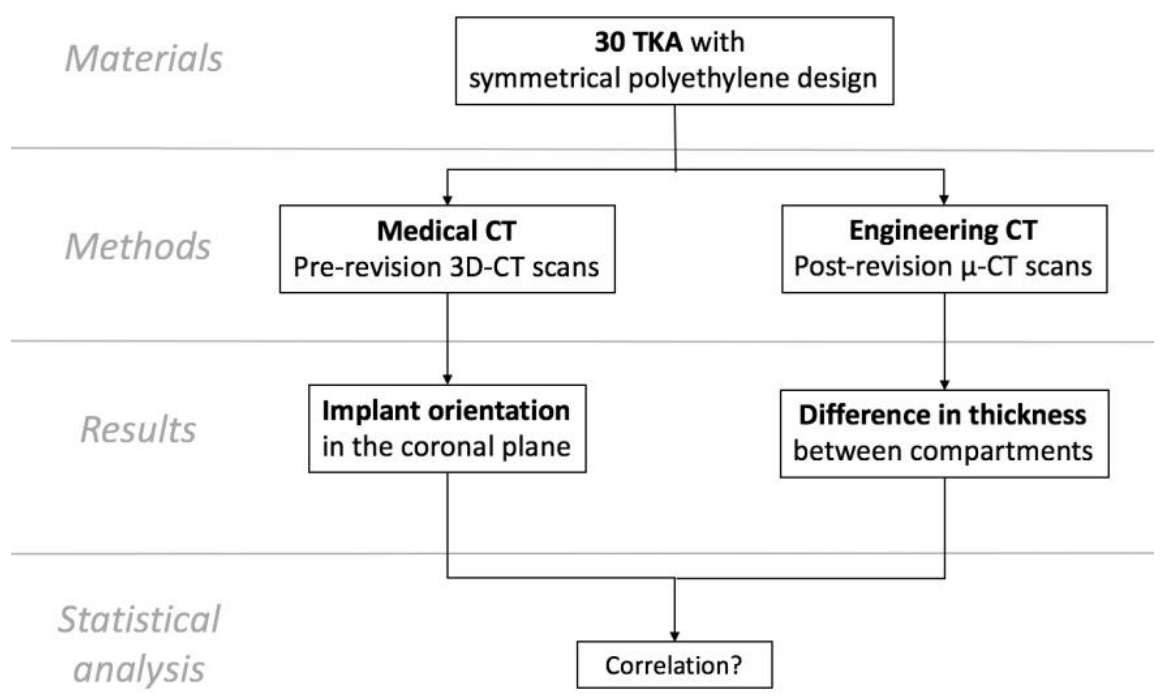

Figure 1: Flow chart representing the steps of our study design.
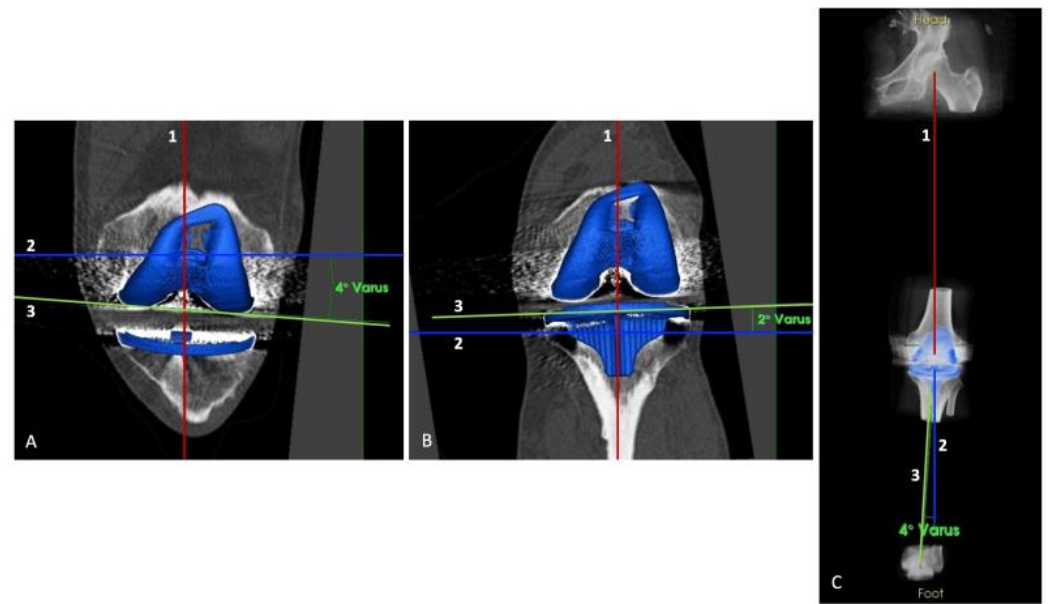

Figure 2: Pre-revision 3DCT images provided accurate and precise information about implant orientation in all the three anatomical planes. Our study focused on coronal orientation: (A) degree of varus/valgus of femoral component, measured as the angle between a line connecting the femoral component distal condyles (3) and a line perpendicular (2) to the mechanical axis of the femur (1); (B) degree of varus/valgus of tibial component, assessed as the angle between a line 
connecting the horizontal face of the tibial component (3) and a line perpendicular (2) to the mechanical axis of the tibia (1); (C) tibiofemoral angle, identified as the angle between the mechanical axis (1) of the femur and the mechanical axis of the tibia (3).

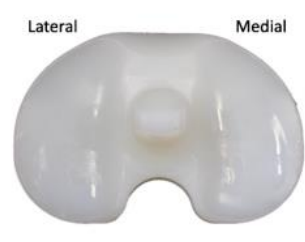

A. Retrieved Polyethylene

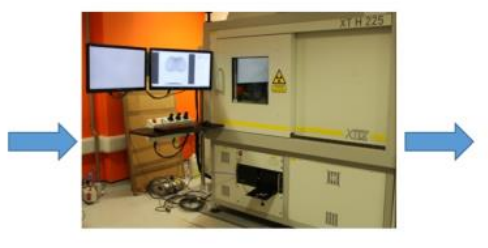

B. Micro-CT Scanner, XTH 225 Nikon

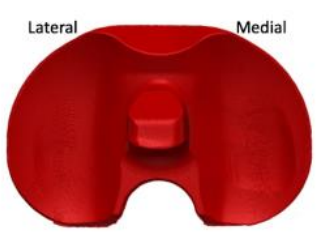

C. Volume Rendering, Simpleware ScanIP

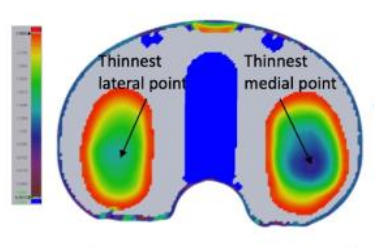

E. Colour Map, Geomagic Control X

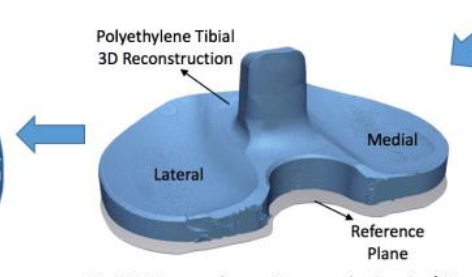

D. 3D Comparison, Geomagic Control X

Figure 3: (A) Example of retrieved left polyethylene from our cohort; (B) micro-CT scanner (XTH 225, Nikon Metrology NV). (C) 3D reconstruction of a left retrieved polyethylene tibial insert, performed using Simpleware ScanIP, with an isotropic resolution of $45 \mu \mathrm{m}$ and a total number of triangles of 10,000,000. (D) Example of alignment between polyethylene tibial 3D reconstruction (blue) and reference plane (grey), imported in Geomagic Control X as measured and reference data respectively. The reference plane was aligned parallel to the backside surface of the tibial insert. (E) Example of colour maps generated in Geomagic Control X for a left polyethylene tibial insert; each colour represented the relative distance between articular surface and reference plane. Zones with the same colour correspond to articular zones at the same distance from the reference plane. For each compartment, the thinnest point was identified (black arrows) and the difference in thickness was computed. The blue pattern in the centre of the figure is due to the design of the backside. 


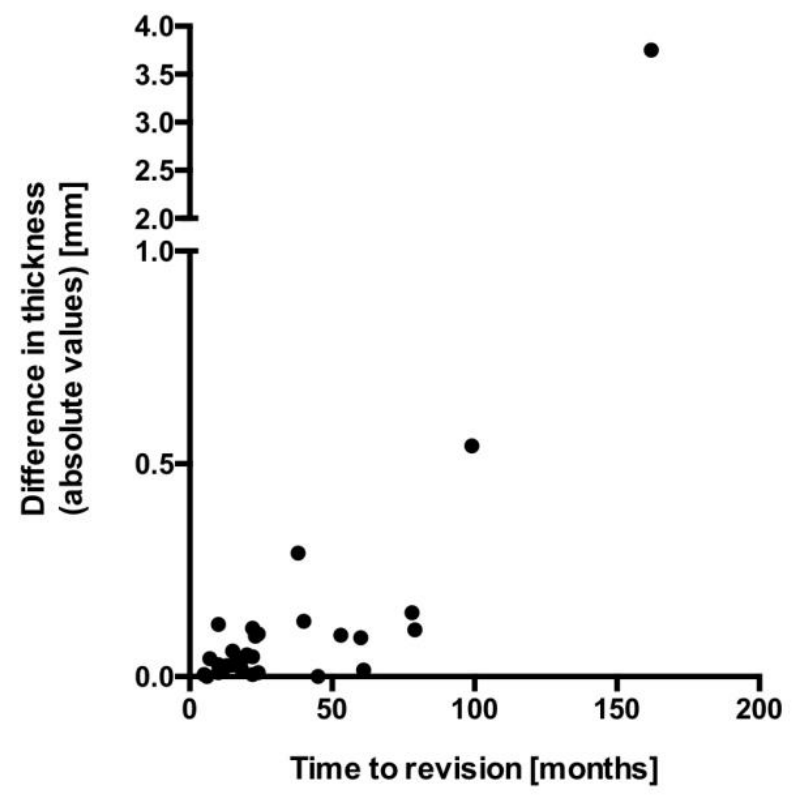

Figure 4: Graph of difference in thickness (in absolute values) and time of implantation: it is possible to see the effect of malorientation for a prolonged time in situ on the difference in thickness between medial and lateral compartment.

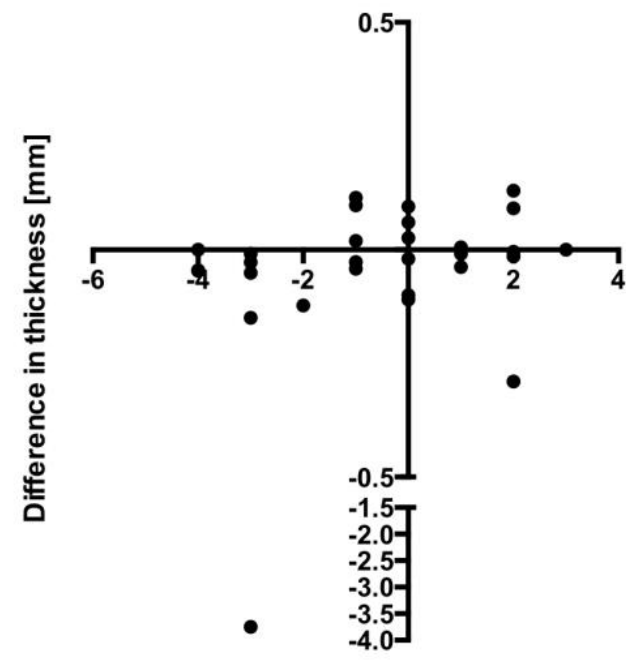

Femoral angle $\left[{ }^{\circ}\right]$

Figure 5: Graph representing the correlation between femoral angle and the difference in thickness. Positive x-values are referred to valgus angulation, whilst negative $\mathrm{x}$-values are referred to varus angulation; positive y-values are referred to smaller lateral compartments, whilst negative y-values are referred to smaller medial compartments. 


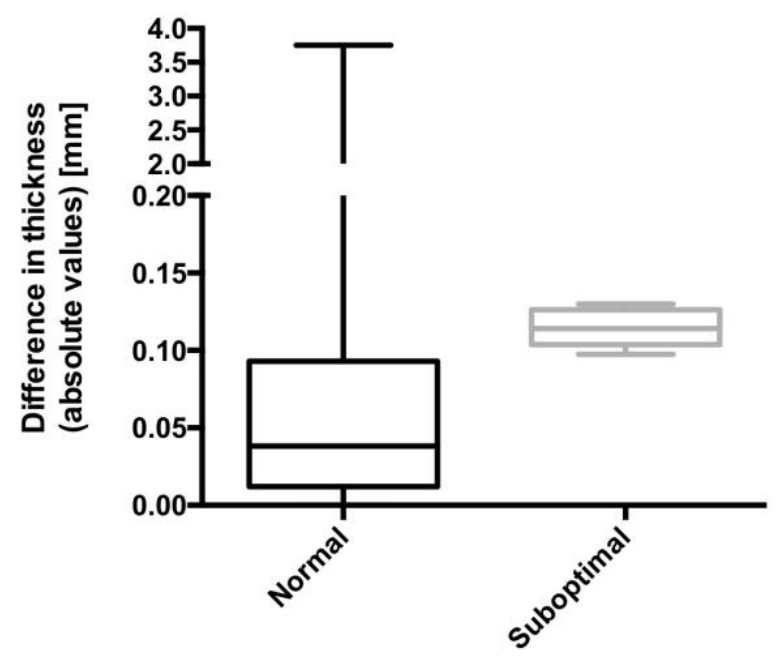

Figure 6: Graph representing the significant difference between normal (within $\pm 3^{\circ}$ ) and suboptimal (outside $\pm 3^{\circ}$ ) tibial orientation: mal-positioned tibial components showed higher difference in thickness than well-positioned ones.

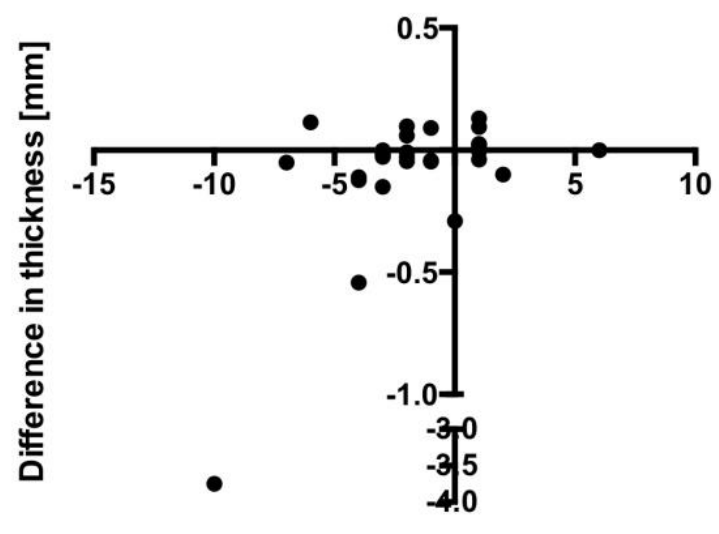

Tibiofemoral angle $\left[{ }^{\circ}\right]$

Figure 7: Graph representing the correlation between tibiofemoral angle and the difference in thickness. Positive x-values are referred to valgus angulation, whilst negative $\mathrm{x}$-values are referred to varus angulation; positive $\mathrm{y}$-values are referred to smaller lateral compartments, whilst negative y-values are referred to smaller medial compartments. 

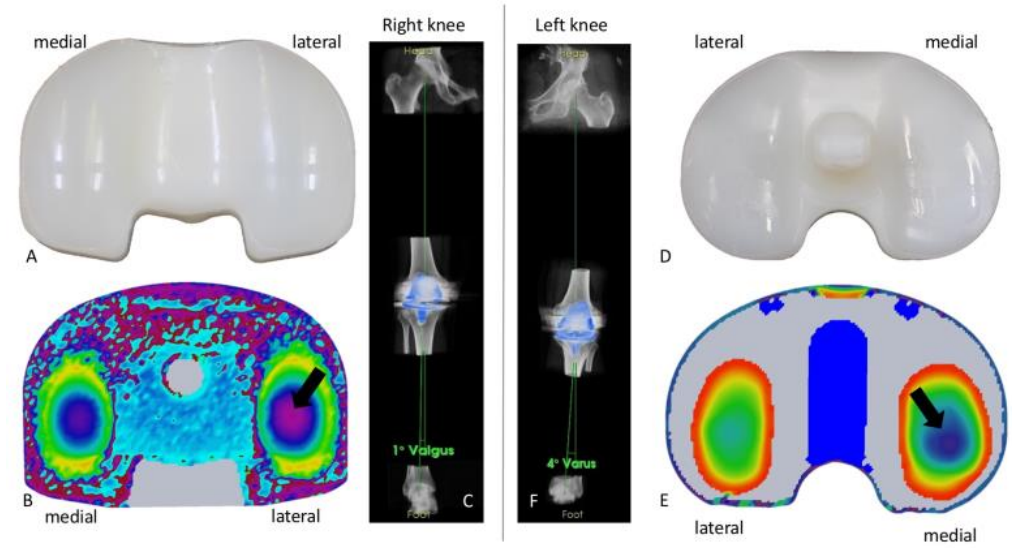

Figure 8: Two examples of correlation between tibiofemoral angle in the coronal plane and differences in linear depth between medial and lateral polyethylene tibial compartments. Left: (A) retrieved right polyethylene tibial insert, on its articular surface is not possible to identify any depression or differences between medial and lateral compartments; (B) colour map, generated by the comparison between 3D rendering of the sample and reference plane, which revealed that the lateral side was a thinner than the medial one (the colour pattern in the centre of the figure is due to the design of the backside); (C) results from pre-revision 3DCT image revealed that the tibiofemoral angle had a valgus orientation, in correlation with results from the retrieval analysis;. Right: (D) retrieved left polyethylene tibial insert, on its articular surface is possible to notice area of burnishing and depression, more extended on the medial side; (E) colour map, generated by the comparison between 3D rendering of the sample and reference plane, which confirmed that the medial side was a thinner than the lateral one (the colour pattern in the centre of the figure is due to the design of the backside); (F) results from pre-revision 3DCT image revealed that the tibiofemoral angle had a varus orientation, in correlation with results from the retrieval analysis.

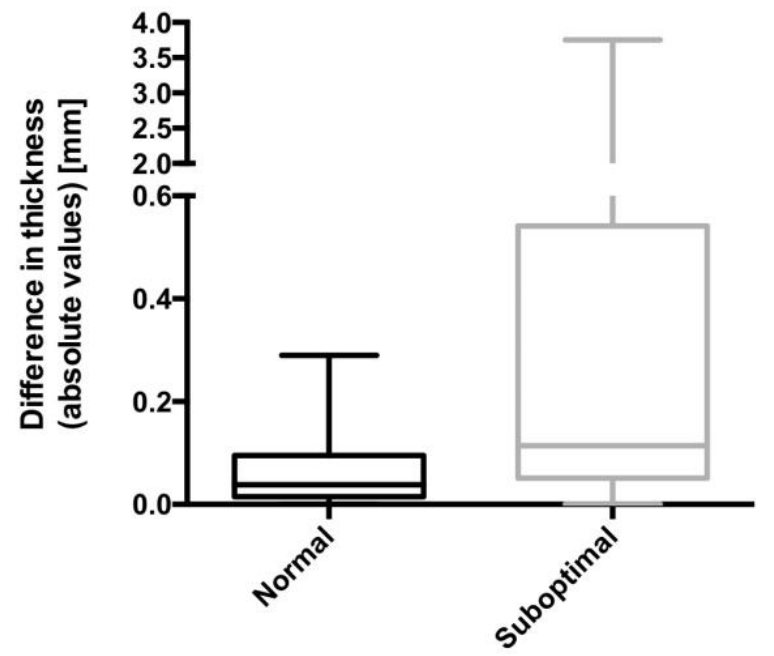

Figure 9: Graph representing the significant difference between normal (within $\pm 3^{\circ}$ ) and suboptimal (outside $\pm 3^{\circ}$ ) tibiofemoral orientation: implants with suboptimal overall alignment showed higher difference in thickness. 


\section{References}

1. Gallo J, Goodman SB, Konttinen YT, Wimmer MA, Holinka M. Osteolysis around total knee arthroplasty: a review of pathogenetic mechanisms. Acta Biomater. 2013;9:8046-8058.

2. Jacobs JJ, Roebuck KA, Archibeck M, Hallab NJ, Glant TT. Osteolysis: basic science. Clin Orthop Relat Res. 2001;393:71-77.

3. Hirschmann MT, Becker R, The Unhappy Total Knee Replacement, 2015, Springer.

4. Armstrong AD, Brien HJ, Dunning CE, King GJ, Johnson JA, Chess DG (2003) Patellar position after total knee

5. Berger RA, Crossett LS, Jacobs JJ, Rubash HE (1998) Malrotation causing patellofemoral complications after total knee arthroplasty. Clin Orthop Relat Res. (356):144-53

6. Nicoll D, Rowley DI, Internal rotational error of the tibial component is a major cause of pain after total knee replacement. J Bone Joint Surg Br. 92(9):1238-44. doi: 10.1302/0301620X.92B9.23516

7. Pang HN, Bin Abd Razak HR, Jamiecson P, Teeter MG, Naudie DD, MacDonald SJ (2016) Factors Affecting Wear of Constrained Polyethylene Tibial Inserts in Total Knee Arthroplasty. J Arthroplasty. 31(6):1340-5. doi: 10.1016/j.arth.2015.12.011

8. Srivastava A, Lee GY, Steklov N, Colwell CW Jr, Ezzet KA, D’Lima DD (2012) Effect of tibial component varus on wear in total knee arthroplasty. Knee. 19(5):560-3. doi: 10.1016/j.knee.2011.11.003

9. Skyttä ET, Lohman M, Tallroth K, Remes V. Comparison of standard anteroposterior knee and hip-to-ankle radiographs in determining the lower limb and implant alignment after total knee arthroplasty. Scand J Surg 2009;98:250-3.

10. Vandekerckhove PTK, Teeter MG, Naudie DD, Howard JL, MacDonald SJ, Lanting BA, 
The Impact of Coronal Plane Alignment on Polyethylene Wear and Damage in Total Knee Replacement: a Retrieval Study, J Arthroplasty (2017), doi: 10.1016/j.arth.2016.12.048.

11. Hirschmann MT, Konala P, Amsler F, Iranpour F, Friederich NF, Cobb JP, The position and orientation of total knee replacement components, J Bone Joint Surg [Br] 2011;93-B:62933.

12. Jazrawi LM, Birdzell L, Kummer FJ, Di Cesare PE, The accuracy of computed tomography for determining femoral and tibial total knee arthroplasty component rotation, J Arthroplasty 2000, https://doi.org/10.1054/arth.2000.8193.

13. Suter T, Zanetti M, Schmid M, Romero J. Reproducibility of measurement of femoral component rotation after total knee arthroplasty using computer tomography. J Arthroplasty $2006 ; 21: 744-8$

14. Harman MK, Banks SA, Kirschner S, Lützner J (2012) Prosthesis alignment affects axial rotation motion after total knee replacement: a prospective in vivo study combining computed tomography and fluoroscopic evaluations. BMC Musculoskelet Disord. 3:206. doi: 10.1186/1471-2474-13-206

15. Hirschmann MT, Iranpour F, Konala P, et al. A novel standardized algorithm for evaluating patients with painful total knee arthroplasty using combined single photon emission tomography and conventional computerized tomography. Knee Surg Sports Traumatol Arthrosc 2010;18:939-44.

16. Pang HN, Jamiecson P, Teeter MG, McCalden RW, Naudie DD, MacDonald SJ, Retrieval Analysis of Posterior Stabilized Polyethylene Tibial Insert and Its Clinical Relevance, J Arthroplasty 2014.

17. Knowlton CB, Bhutani P, Wimmer MA (2016) Relationship of surface damage appearance and volumetric wear in retrieved TKR polyethylene liners. J Biomed Mater Res Part B. doi: 10.1002/jbm.b.33684.

18. Teeter MG, Milner JS, Au JL, Lorusso D, Naudie DD, Holdsworth DW, Regional 
Measurements of Surface Deviation Volume in Worn Polyethylene Joint Replacement Component, Journal of Long-Term Effects of Medical Implants, 20(1): 49-56 (2010)

19. Engh CA, Zimmerman RL, Hopper RH, Engh GA, Can Microcomputed Tomography Measure Retrieved Polyethylene Wear? Comparing Fixed-bearing and Rotating-platform Knees, Clin Orthop Relat Res (2013) 471:86-93 DOI 10.1007/s11999-012-2513-2.

20. Henckel J, Richards R, Lozhkin K, Harris S, Rodriguez y Baena FM, Barrett ARW, Cobb JP (2006) Very low-dose computed tomography for planning and outcome measurement in knee replacement. The Imperial Knee Protocol. J Bone Joint Surg [Br]. 88-B:1513-18

21. Gromov K, Korchi M, Thomsen MG, Husted H, Troelsen A (2014) What is the optimal alignment of the tibial and femoral components in knee arthroplasty? An overview of the literature. Acta Orthop. 85(5):480-7. doi: 10.3109/17453674.2014.940573

22. Lingaraj K, Morris H, Bartlett J. Polyethylene thickness in unicompartmental knee arthroplasty. Knee. 2011;18:165-7.

23. D’Lima DD, Hermida JC, Chen PC, Colwell CW. Polyethylene wear and variations in knee kinematics. Clin. Orthop. Relat. Res. 2001:124-30.

24. Collier MB, Engh CA, McAuley JP, Engh GA, Factors Associated with the Loss of Thickness of Polyethylene Tibial Bearings After Knee Arthroplasty, the Journal of Bone and Joint Surgery 89(6):1306-14

25. Ritter M, Davis KE, Meding JB, Pierson JL, Berend ME, Malinzak R a. The effect of alignment and BMI on failure of total knee replacement. J. Bone Joint Surg. Am. 285 2011;93:1588-96

26. Wasielewski RC, Galante JO, Leighty RM, Roseneberg AG (1994) Wear patterns on retrieved polyethylene tibial inserts and their relationship to technical consideration during total knee arthroplasty. Clin Orthop Relat Res. (299):31-43. 
27. Lonner JH, Laird MT, Stuchin SA. Effect of rotation and knee flexion on radiographic alignment in total knee arthroplasties. Clin Orthop Relat Res. 1996;331:102-6.

28. Yamada K, Imaizumi T. Assessment of relative rotational alignment in total knee arthroplasty: usefulness of the modified Eckhoff method. J Orthop Sci. 2000;5:100-3.

29. Yau WP, Chiu KY, Tang WM (2007) How precise is the determination of rotational alignment of the femoral prosthesis in total knee arthroplasty: an in vivo study. J Arthroplasty. 22(7):1042-8.

30. Berger RA, Rubash HE, Seel MJ, Thompson WH, Crossett LS, Determining the rotational alignment of the femoral component in total knee arthroplasty using the epicondylar axis. Clin Orthop 1993;286:40-7

31. Teeter MG, Milner JS, MacDonald SJ, Naudie DD, Manufacturing lot affects polyethylene tibial insert volume, thickness, and surface geometry, Proceedings of the Institution of Mechanical Engineers, Part H: Journal of Engineering in Medicine, Vol 227, Issue 8, pp. $884-889$.

32. Teeter MG, Naudie DDR, Bourne RB, et al. How do CAD models compare with reverse engineered manufactured components for use in wear analysis? Clin Orthop Relat Res 2011; 470(7): 1847-1854.

33. Teeter MG, Naudie DDR, Milner JS, Holdsworth DW, Determination of Reference Geometry for Polyethylene Tibial Insert Wear Analysis, J Arthroplasty 26(3):497-503, March 2010, DOI: 10.1016/j.arth.2010.01.096

34. Goldvasser D, Hansen VJ, Noz ME, Zeleznik MP, Olivecrona H, Bragdon CR, Weidenhielm L, Malchau H. In vivo and ex vivo measurement of polyethylene wear in total hip arthroplasty. Acta Orthop. 2014 
35. Gbejuade HO, White P, Hassaballa M, Porteous AJ, Robinson JR, Murray JR. Do long leg supine CT scanograms correlate with weight-bearing full-length radiographs to measure lower limb coronal align- ment? Knee. 2013. doi:10.1016/j.knee.2013.05.009

36. Schlatterer B, Suedhoff I, Bonnet X et al (2009) Skeletal land- marks for TKR implantations: evaluation of their accuracy using EOS imaging acquisition system. Orthop Traumatol Surg Res 95:2-11. doi:10.1016/j.otsr.2008.05.001

37. Meijer MF, Boerboom AL, Stevens M et al (2014) Assessment of prosthesis alignment after revision total knee arthroplasty using EOS 2D and 3D imaging: a reliability study. PLoS One 9:e104613. doi:10.1371/journal.pone.0104613

38. Melhem E, Assi A, El Rachkidi R, Ghanem I, EOS ${ }^{\circledR}$ biplanar X-ray imaging: concept, developments, benefits, and limitation, J Child Orthop (2016) 10:1-14 DOI $10.1007 / \mathrm{s} 11832-016-0713-0$ 